\title{
Quantifying Rapid Urbanization and its impact on Urban Green Spaces: Directional and Zonal Analysis integrated with Landscape Expansion Index
}

\author{
Eyasu markos woldesemayat ${ }^{1}$ \\ ${ }^{1}$ Tianjin University
}

November 30, 2020

\begin{abstract}
Addis Ababa, the capital of Ethiopia, is urbanizing rapidly in recent years mainly through the destruction of environmental resources. This study aimed at the dynamics of urban green spaces (UGS). Remote Sensing and Geographical Information System (GIS) was used to extract land use and land cover data. The Landscape Expansion Index (LEI) was employed to measure urban growth patterns. The result showed that a more noticeable growth was observed in the peri-urban zone $(40.1 \mathrm{~km} 2$ to $176.1 \mathrm{~km} 2$ ), followed by the inner urban zone (from $67.1 \mathrm{~km} 2$ to $105 \mathrm{~km} 2$ ). The expansion in the urban core zone was marginal and followed a non-unidirectional trend i.e. increased in the first period (1989-1999) and second period (1999-2009) by $(0.11 \%$ and $4.2 \%)$, while decreased in the third period (2009-2019) by $3.6 \%$. The result for LEI dynamics showed that the city experienced a pronounced outlying growth (98\%) pattern, while edge expansion and infilling growth were insignificant. Conversely, the UGS declined in the inner urban zone by (18.03\%), (28.61\%) and (18.97\%) in the first, second, and third periods. Similarly, in the peri-urban zone, the UGS persistently declined by (11.5\%), (17.1\%) and, (28.03\%). The directional analysis showed that urban areas significantly expanded in SEE, SSE, SSW, and NEE with a net increase of 5.35, 4.4 km, 2.83, and $2.3 \mathrm{~km} 2$ /year, respectively. Conventional large-scale / citywide/ dynamics investigations are not robust enough to represent the actual magnitude and directions of change, while the zonal and directional study is more effective in characterizing the Spatio-temporal dynamics for better urban planning towards.
\end{abstract}

\section{Hosted file}

Manuscript with author detail.pdf available at https://authorea.com/users/379796/articles/ 496016-quantifying-rapid-urbanization-and-its-impact-on-urban-green-spaces-directionaland-zonal-analysis-integrated-with-landscape-expansion-index

\section{Hosted file}

Figures.pdf available at https://authorea.com/users/379796/articles/496016-quantifyingrapid-urbanization-and-its-impact-on-urban-green-spaces-directional-and-zonal-analysisintegrated-with-landscape-expansion-index 